\title{
EL FEDERALISMO JUDICIAL ESTADOUNIDENSE
}

\author{
Rosario Serra Cristóbal
}

doi: http://dx.doi.org/10.18543/ed-65(1)-2017pp301-330

\begin{abstract}
SUMARIO: 1 . Un PODER JUDICIAL A IMAGEN DEL ESTADO FEDERAL EN QUE SE INSERTA. 2. UNA ORGANIZACIÓN JURISDICCIONAL DUALISTA. 2.1. La organización jurisdiccional federal. 2.2. La jurisdicción estatal estadounidense. 3. LA ARTICULACIÓN ENTRE LA JURISDICCIÓN FEDERAL Y LA JURISDICCIÓN ESTATAL. 4. EL GOBIERNO DEL PODER JUDiCIAL EN ESTADOS UNiDOS. 5. El ESTATUTO JUDiCIAL: LA SELECCIÓN, PROMOCIÓN, INDEPENDENCIA Y RESPONSABILIDAD DE LOS JUECES. 5.1. Un sistema de selección de jueces plural. 5.2. La promoción judicial. 5.3. Jueces independientes y responsables. 6. ALGUNAS REFLEXIONES FINALES EN TORNO A LA INTERSECCIÓN ENTRE LAS ORGANIZACIONES JUDICIALES ESTATALES Y FEDERAL.
\end{abstract}

\section{UN PODER JUDICIAL A IMAGEN DEL ESTADO FEDERAL EN QUE SE INSERTA}

Hablar del sistema judicial estadounidense es hablar de 51 sistemas judiciales, 50 estatales y uno federal, es abordar un sistema federal judicial creado siguiendo la senda del propio federalismo del país. Como decía Blanco Valdés, «el federalismo americano, en gran medida como fruto de su historia irrepetible, es verdaderamente peculiar» ${ }^{1}$ y esa afirmación puede mantenerse, como se demostrará en este trabajo, también respecto del poder judicial.

${ }^{1}$ Roberto Blanco VAldés, Los rostros del federalismo, (Madrid: Alianza Editorial, 2012), 164. 
La federación es una construcción creada precisamente por la Constitución de los Estados Unidos de América (EEUU) en $1787^{2}$. Cada uno de los Estados que conformaron los Estados Unidos tenían en su origen (y mantienen) su Parlamento, su gobierno y sus Tribunales, y con la federación se vino a crear un Parlamento, un Gobierno y unos Tribunales, adicionales, todos ellos federales y por lo tanto comunes a todos los Estados.

En lo que a la conformación del poder judicial se refiere, el modelo judicial adoptado en Estados Unidos resulta del establecimiento de una dualidad jurisdiccional, la federal y la estatal, lo cual se traduce en que el poder judicial está compuesto de dos niveles jurisdiccionales independientes uno del otro. En la cúspide del poder judicial los padres constituyentes ubicaron al Tribunal Supremo como parte del plan federal del nuevo Estado. Como recuerda Blanco Valdés, «De hecho, el transcurso del tiempo pronto iba a demostrar la importancia decisiva del Supremo como instrumento para hacer efectiva la vigencia no sólo del derecho federal sino también de la que era su máxima expresión, es decir, de la Constitución aprobada en Filadelfia» ${ }^{3}$. El protagonismo y poder del Tribunal Supremo norteamericano es de sobra conocido y ha dado muestras de su importancia en las disyuntivas que EEUU ha tenido que afrontar en momentos cruciales ${ }^{4}$.

Efectivamente, en la evolución del federalismo norteamericano hay que reconocer un importante protagonismo al poder judicial y, en concreto, al Tribunal Supremo norteamericano. Así, se señala el periodo de la Presidencia de Roger B. Taney en el Tribunal Supremo (1836-1864) como un periodo en el que se impulsó especialmente el federalismo dual, donde el principio central que iluminó la interpretación de la Constitución era el principio del equilibrio federal, según el cual la distribución de poderes entre el poder nacional y los estados era algo esencialmente fijo e inmutable y la idea de que el orden federal se caracteriza sobre todo por la existencia de dos esferas de gobierno (la estatal y la federal) separadas e independientes entre sí ${ }^{\prime}$. Tras ese periodo, el Tribunal Supremo mantuvo una acción sostenida contraria a la acción legislativa del Gobierno federal y algunas leyes también estatales. El verdadero cambio será notable tras la gran depresión. En los primeros años, el nuevo federalismo cooperativo intentó ser frenado por la mayoría del Tribunal Supremo, hasta tal punto que el Presidente Roosevelt presentó un

${ }^{2}$ Sobre el origen del Federalismo véase el magnífico trabajo de BLANCO VALDÉs: Los rostros ..., pp. 46 y ss.

3 Ibidem, p. 54.

${ }^{4}$ Sobre el importante poder del Tribunal Supremo y la necesidad, según algunos autores, de frenar ese exceso de poder puede verse, James MACGREGOR BuRnS, Packing the Court, (New York: Penguin Books, 2010).

5 Blanco Valdés, Los rostros del federalismo..., 245. 
proyecto de normativa, que finalmente no se aprobó, que pretendía modificar la composición del Tribunal Supremo para obtener una formación menos conservadora que facilitase la pervivencia de las nuevas leyes federales intervencionistas que iban aprobándose. No obstante, acabó produciéndose un giro en los criterios de algunos jueces tradicionalmente conservadores y tomó cuerpo un histórico cambio de doctrina que dejó patente su disposición a aceptar la intervención pública en la economía ${ }^{6}$.

Así pues, el poder judicial estadounidense es producto e imagen del propio modelo federal de este país y a su vez ha colaborado, especialmente su Tribunal Supremo, al devenir de ese federalismo.

En los siguientes puntos analizaremos cómo se manifiesta ese federalismo dual en la organización del poder judicial, las competencias que se atribuyen a los diferentes Tribunales y cómo se articulan, quién tiene capacidad de crear nuevos órganos jurisdiccionales, a quién corresponde el gobierno de estos Tribunales, y cómo se designan los jueces que los conforman. Y por último, se advertirá de que esa estancaneidad entre la organización jurisdiccional federal y la estatal tienen sus lógicas quiebras derivadas de la actuación bajo un mismo ordenamiento encabezado por la Constitución federal.

\section{UNA ORGANIZACIÓN JURISDICCIONAL FEDERAL DUALISTA}

El principio federal tiene sus efectos sobre la organización del poder judicial, encontrándonos, como se ha adelantado más arriba, con órganos jurisdiccionales vinculados al Estado federal y una organización jurisdiccional estatal vinculada a cada uno de los Estados. Se trata de la confluencia de organizaciones judiciales que están separadas, aunque relacionadas entre sí en algún aspecto.

En el caso de EEUU, esta federalización del poder judicial no deriva de una imposición Constitucional, pues el art. III hace referencia al poder judicial sin apellidos, aunque de su lectura y de las funciones que al Tribunal Supremo y a otros Tribunales les otorga se deriva que está haciendo referencia a la jurisdicción federal. De hecho, cuando se aprobó la Constitución estadounidense y se crearon los Estados Unidos de América, los Estados integrantes ya tenían aprobadas sus propias Constituciones donde la organización jurisdiccional de ellos quedaba definida. Es pues en las Constituciones de los Estados miembros donde se encuentra la regulación de la jurisdicción estatal.

${ }^{6}$ Ibidem, p. 255. 


\subsection{La organización jurisdiccional federal}

Como decíamos, la Constitución estadounidense únicamente hace referencia al poder judicial federal. De hecho, tan solo menciona al Tribunal Supremo en el art. $\mathrm{III}^{7}$, aunque deposita el poder judicial igualmente «en los Tribunales (federales) inferiores que el Congreso instituya y establezca en lo sucesivo».

Igualmente se reitera esta facultad en el art. I sección 8.9 cuando atribuye al Congreso la potestad para crear Tribunales inferiores a la Corte Suprema. Fue la Judiciary Act de 1789 la que estableció la existencia de dos niveles de Tribunales federales inferiores al Tribunal Supremo: las District Courts y las Circuit Courts. Estas segundas fueron sustituidas a partir de 1891 cuando se empezaron a crear las Circuit Courts of Appel, como Tribunales de apelación. Durante las primeras décadas el número de Tribunales federales fue muy limitado. La judicatura federal fue aumentando con el tiempo, experimentando su crecimiento más notable tras la Segunda Guerra Mundial.

Así, haciendo uso de la facultad del art. I de la Constitución, el Congreso ha creado algunos Tribunales para cumplir con determinadas cuestiones específicas: 3 District Courts in Guam, U.S. Virgin Islands, y la de Northen Mariana Islands; y 5 Tribunales que tienen jurisdicción en todo el ámbito federal para determinadas materias: la U.S. Tax Court, la U.S. Court of Federal Claims 8 , la U.S. Court of Appeals for Veterans Claims, la U.S. Court of International Trade y la Foreing Intelligence Surveillance Court, que se encarga de resolver las gestiones para implementar sistemas de seguridad nacional.

La Constitución norteamericana incluyó un listado de las materias que corresponden al conocimiento de los Tribunales federales, que solamente pueden conocer de asuntos cuando se presentan en forma de un verdadero conflicto de intereses o de derechos entre partes enfrentadas, no caben planteamientos abstractos o hipotéticos. Según el Art. III sección 2 de la misma,

«El Poder Judicial entenderá en todas las controversias, tanto de Derecho como de equidad, que surjan como consecuencia de esta Constitución, de las leyes de los Estados Unidos y de los tratados celebrados o que se

7 Art. III Constitución EEUU: «Se depositará el poder judicial de los Estados Unidos en una Corte Suprema y en los Tribunales inferiores que el Congreso instituya y establezca en lo sucesivo. Los jueces, tanto de la Corte Suprema como de los Tribunales inferiores, continuarán en el ejercicio de sus funciones mientras observen buena conducta y recibirán en periodos fijos una remuneración por sus servicios que no será disminuida durante el tiempo de su nombramiento».

${ }^{8}$ Conoce en primera instancia de reclamaciones económicas contra la Federación, minorías indias, propiedad intelectual... Sus 16 jueces son nombrados por el Presidente, con la opinión y el consentimiento del senado, por un periodo de 15 años (28 U.S.C. 171-2). 
celebren bajo la autoridad de los Estados Unidos; en todas las controversias que se relacionen con Embajadores, otros Ministros públicos y Cónsules; en todas las controversias de la jurisdicción marítima y de almirantazgo; en las controversias en que los Estados Unidos sea una parte; en las controversias entre dos o más Estados; entre ciudadanos de diferentes Estados (diversity of citizeship jurisdiction) ${ }^{9}$, entre ciudadanos del mismo Estado que reclamen tierras en virtud de concesiones de diferentes Estados, y entre un Estado o los ciudadanos del mismo y Estados, ciudadanos o súbditos extranjeros ${ }^{10} \gg$.

La mayoría de las controversias relativas a las materia indicadas son resueltas por los Tribunales federales de Distrito (District Courts), generalmente unipersonales, que constituyen la instancia inferior. Suman un total de 94 distritos judiciales entre los 50 Estados $^{11}$.

Sus decisiones pueden ser revisadas por las Courts of Appeal de su Circuito, también llamadas Circuit Courts, que están conformadas por tres jueces. Estos Tribunales de Apelación o Circuit Courts se organizan en torno a 13 circuitos judiciales, con un Tribunal de apelación en cada uno de ellos. Es decir, hay una Court of Appeal por cada uno de los 12 circuitos regionales más la Court of Appeals for the Federal District Court. (Y a ellos hay que añadir la U.S. Court of Appeals for the Armed Forces). Estos Tribunales no revisan los hechos, ni practican la prueba de nuevo, sino que se centran en el análisis de cuestiones de Derecho.

Y por último, cabe la posibilidad de recurrir ante el Tribunal Supremo de la Federación. El Tribunal Supremo, formado por su presidente (Chief Justice) y 8 Associate Justices, se encuentra en la cúspide de la pirámide judicial y por lo tanto se constituye en la última instancia en todo el territorio. Tiene dos funciones: Por un lado, se encuentra la de ser la última instancia de apelación, que ejerce con la potestad de escoger discrecionalmente los casos que resolverá (certiorari), salvo en unos escasos supuestos en los que

${ }^{9}$ Cuando un caso afecta a ciudadanos de diferentes Estados, éste puede ser conocido por un Tribunal federal. Es lo que se denomina removal to a Federal Court when diversity of citizeship jurisdiction exists.

${ }^{10}$ La reforma de la Constitución más relevante en cuanto a las competencias de los Tribunales federales se produjo con la aprobación de la Enmienda XI que limitó las facultades de los poderes federales.

Enmienda XI: «El poder judicial de los Estados Unidos no debe interpretarse en el sentido de que se extienda a cualquier litigio de derecho estricto o de equidad que se inicie o prosiga contra uno de los Estados Unidos por ciudadanos de otro Estado o por ciudadanos o súbditos de cualquier Estado extranjero»».

${ }^{11}$ Una imagen de esa distribución puede verse en la siguiente fuente: https://saylordotorg.github.io/text_law-for-entrepreneurs/s06-01-the-relationship-between-state.html. Acceso el 6 marzo 2017 . 
obligatoriamente tiene que revisar la decisión judicial previa (Appellate Jurisdiction $)^{12}$. Y, por otro lado, es juez de primera instancia en unas pocas materias: de forma exclusiva en conflictos entre estados (Exclusive Original Jurisdiction); y en casos sobre embajadores y otros ministerios públicos y consulados, controversias entre un Estado y los Estados Unidos y las acciones o procedimientos de un Estado contra ciudadanos de otro Estado o contra extranjeros (Non Exclusive Original Jurisdiction). En estos casos de jurisdicción de instancia no exclusiva, el Tribunal Supremo puede determinar su propia jurisdicción o decidir si le corresponde a los Tribunales Federales inferiores o a los Tribunales estatales.

En la práctica, la facultad de ejercer el certiorari hace que los casos que finalmente revise el Tribunal Supremo constituyan un porcentaje realmente bajo $^{13}$, por lo tanto, la mayoría de los asuntos se resuelven en última instancia ante los Tribunales federales de apelación.

\subsection{La jurisdicción estatal estadounidense}

La organización judicial estatal viene establecida en las Constituciones propias de los Estados y en las leyes aprobadas por el legislador doméstico al respecto.

Los Tribunales estatales no se organizan en todos los Estados del mismo modo. Algunos presentan una organización relativamente simple, como es el caso de California, y otros incluyen una organización jurisdiccional muy compleja con un número muy amplio de Tribunales especializados, como en Nueva York ${ }^{14}$. De todos modos, para simplificar, podemos decir que el poder judicial a nivel estatal se organiza igualmente en tres niveles $u$ órdenes que son: El Tribunal Supremo del Estado o Tribunales estatales de última instancia, situado en la cúspide; en un segundo nivel, los Tribunales intermedios de apelación (Intermediate Appellate Courts); y en un tercer grado los Trial Courts y otros Tribunales inferiores o Tribunales especializados.

${ }_{12}$ En los supuestos de redistribución de representantes en las Cámaras, de normas sobre derecho de voto, antimonopolio, o de aplicación de normas sobre la campaña electoral presidencial. Han sido escasos los casos.

${ }_{13}$ De los 8000 casos que anualmente recibe, solo son admitidos unos 100 . Generalmente entra a conocer cuando los casos refieren a principios legales inusualmente importantes o cuando dos o más Tribunales federales o Tribunales estatales han interpretado el Derecho federal de modo diferente, Toni M. FINE, An introduction to the anglo-american legal system, (Pamplona: Thomson/Aranzadi, 2007), 103.

14 Mayor información a este respecto puede consultarse en Pamela C. CORLEY, Artemus Ward, Wendy L. MartíneK: American Judicial Process. Myth and Reality in Law and Courts, (New York: Routledge, 2016), 106 y ss. 
Todos los Estados tienen un Tribunal de última instancia, que pueden recibir un nombre distinto dependiendo del Estado: Court of Appeals en New York, Maryland y District of Columbia, Supreme Judicial Court en Main y Massachussets, State Supreme Court en la mayoría de los Estados, Supreme Court of Appeals en West Virginia, o simplemente State Supreme Court en el resto de Estados. La única excepción la aportan Texas y Oklahoma que tienen dos Tribunales de última instancia uno para asuntos civiles (Supreme Court) y otro para asuntos criminales (Court of Criminal appeals).

Al Tribunal Supremo de cada Estado le corresponde ser el máximo intérprete de la Constitución del Estado y generalmente se constituyen en la última instancia de apelación de las decisiones del resto de Tribunales del Estado. Resuelven conflictos sobre la interpretación de la ley que puedan suscitarse en instancias judiciales inferiores o sobre otros asuntos conocidos previamente por dichos Tribunales.

En un segundo nivel se encuentran los Tribunales estatales de apelación. Treinta y cinco Estados tienen un Tribunal intermedio de apelación, cinco Estados tienen dos (Alabama, Indiana, New York, Pennsylvania y Tennessee) y los siguientes no tienen Tribunales intermedios de apelación, por lo que el Tribunal de última instancia es el que se convierte siempre en su instancia de apelación: District of Columbia y los Estados de Delaware, Maine, Montana, Nevada, New Hampshire, North Dakota, Rodhe Island, South Dakota, Vermont, West Virginia y Wyoming ${ }^{15}$.

Estos Tribunales de Apelación realizan una labor de revisión en apelación de la gran mayoría de decisiones adoptadas por los Tribunales de primera instancia ${ }^{16}$. Aunque los justiciables pueden solicitar que la apelación de su caso sea conocida directamente por el Tribunal de última instancia (el Tribunal Supremo del Estado), excepcionalmente se accede a tales peticiones. Por lo tanto, el bloque mayoritario de apelaciones es resuelto por estos Tribunales, es decir, la apelación de todas las decisiones firmes adoptadas por los Tribunales de primera instancia (Trial Courts) que no sean recurribles directamente ante el Tribunal Supremo estatal. Además, aunque las decisiones adoptadas por estos Tribunales intermedios son recurribles ante Tribunal Supremo del Estado, éste, al igual que el Tribunal Supremo de Estados Unidos, tiene amplios poderes de discreción para admitir o rechazar el recurso.

${ }^{15}$ Los nombres utilizados para denominar a estos Tribunales de nuevo varían según el Estado. Por ejemplo, en Alabama y Oklahoma se denominan Court of Civil Appeals y Court of Criminal Appeals, en Indiana Court of Appeals y Tax Court, en New York Appellate Division of Supreme Court y Apellate Terms of Supreme Court, en Pennsylvania Superior Court y Commonwealth Court, etc.

${ }_{16}$ Muchos Tribunales Intermedios de Apelación tienen también competencia para revisar actuaciones de agencias estatales en relación a los deberes del poder ejecutivo. 
De hecho, el 95\% de las decisiones acaban agotando su última instancia en los Tribunales de Apelación.

El escalafón jurisdiccional más bajo lo conforman las Trial Courts, que pueden ser de jurisdicción general o pueden no serlo. De nuevo la denominación de estos Tribunales es de lo más variopinta y puede llevar a confusión. A veces se denominan District Courts, Circuit Courts, o incluso Superior Courts. Todos los Estados tienen al menos un Tribunal de este tipo con jurisdicción general, donde se conocen de las causas criminales y civiles más importantes (delitos contra las personas o la propiedad, delitos de drogas, disolución de vínculos matrimoniales, propiedad, responsabilidad civil a partir de determinadas cuantías, recursos contra agencias administrativas y apelación de casos dictados por Tribunales más inferiores).

En este nivel inferior del poder judicial se encuentran también otros Tribunales de los que se dice que no tienen jurisdicción general porque:

a) Están especializadas en el conocimiento de materias concretas. Muchas veces actúan como una división del Tribunal estatal de Jurisdicción general. Así podemos encontrarnos con: Juvenile Courts (asuntos de menores), Family Courts (matrimonio, relaciones custodia parental, etc.), Drug Courts (drogas), Probate, Orphan y Surrogate Courts (herencia, orfandad, declaraciones incapacidad...).

b) $\mathrm{O}$ son Tribunales de jurisdicción limitada ${ }^{17}$, que son los Tribunales con los que los ciudadanos acaban teniendo mayor contacto. Aproximadamente el $60 \%$ de los casos son conocidos por estos Tribunales. Puede ser: Magistrate Court (delitos menores y faltas y asuntos civiles de escasa cuantía), Municipal Court (daños contra bienes municipio, salud pública...), Community Court (sólo en algunos Estados para delitos graves contra la «calidad de vida»), Traffic Court (tráfico), Small Claims Court (asuntos civiles de muy escasa cuantía), Justice of the peace.

En general, los Tribunales estatales conocen del resto de materias no reservadas a los Tribunales federales ${ }^{18}$. De hecho, cualquier caso puede ser llevado ante una Corte estatal, salvo que haya una ley federal que exija que esa cuestión sea conocida por un Tribunal federal. Por citar un dato, el 90\%

17 Pueden verse por Estados en http://www.judicialselection.us/judicial_selection/ methods/limited_jurisdiction_courts.cfm?state=

${ }_{18}$ Calvin MASSEY, «Standing in State Courts, State Law, and Federal Review», Duq. Law Review, n. ${ }^{\circ}$ 53, (2015): 401-411. Esos supuestos de reserva a los Tribunales federales prácticamente se reducen a que el acusado sea los Estados Unidos y aquellos relativos a la aplicación de determinadas leyes federales como las antimonopolio, patentes y copyright, quiebra, Derecho marítimo y delitos contra la propiedad federal. 
de las causas civiles y criminales en EEUU son conocidas por los Tribunales estatales $^{19}$.

Hay casos que por la materia pueden ser planteados ante la jurisdicción federal y ante los Tribunales estatales y muchos litigantes han preferido hacerlo ante estos últimos con la esperanza de obtener una sentencia más protectora de los derechos civiles que las esperables de los Tribunales federales o, si prospera el certiorari, del Tribunal Supremo, que ha mantenido en muchos momentos un perfil mayoritariamente conservador. A esa recurrente inclinación de los Tribunales Supremos estatales de ampliar los derechos civiles más allá de cómo lo son a nivel federal se conoce con el nombre de «nuevo federalismo judicial $»^{20}$. Esta forma de proceder se inició en la década de 1970 cuando, ante un cambio de las mayorías en el Tribunal Supremo federal y temiendo que el conservadurismo erosionara los avances obtenidos en derechos civiles, los abogados y asociaciones de derechos comenzaron a confiar en las Cartas de derechos de las Constituciones estatales y en los Tribunales estatales como mejores garantes de tales derechos. Y ello a pesar de que dichos Tribunales no habían sido tradicionalmente especialmente beligerantes o protectores de los derechos civiles. La tendencia se ha mantenido hasta la actualidad, incluso abriéndose paso al planteamiento de controversias que no se han planteado ante el Tribunal Supremo federal, como cuestiones en relación a los derechos de gays y lesbianas. Ello ha dado un vuelco al sistema y parece que en materia de derechos el Derecho federal proporciona el mínimo constitucional, la base de la que partir, y los Tribunales estatales sobre esa base están aportando una protección adicional.

\section{LA ARTICULACIÓN ENTRE LA JURISDICCIÓN FEDERAL Y LA JURISDICCIÓN ESTATAL}

De entrada, la jurisdicción federal y la jurisdicción estatal funcionan como dos sistemas independientes, sin embargo, hay puntos en los que se produce una articulación entre una jurisdicción y otra. Por un lado, porque el reparto de materias en un Estado federal nunca es estanco y hay materias concurrentes entre la Federación y $\operatorname{los} \operatorname{Estados}^{21}$ que conducen a una

${ }^{19}$ FINE, An introduction to the anglo-american legal system..., 47.

${ }^{20}$ Craig F. EMMERT y Carol ANN TRAUT, «Issues and outcomes in state supreme court judicial review cases», Southeastern Political Review, vol. 28, n. ${ }^{\text {o } 2, ~(2000): ~} 296$.

${ }^{21}$ Por poner un ejemplo, con pocas excepciones, los casos civiles que se podrían presentar en un tribunal federal (casos surgidos bajo la competencia federal) pueden ser también iniciados ante los Tribunales estatales. Los casos en los que se alega diversity of citizenship (nacionales de distintos estados) son conocidos según la cuantía por Tribunales federales o por Tribunales estatales. Con el tiempo también se ha producido una fede- 
asignación de los casos no siempre clara entre los Tribunales federales y los Tribunales estatales.

Por otro lado, el papel de norma suprema que juega la Constitución estadounidense genera una necesidad de uniformidad en la aplicación constitucional de la ley que otorga un protagonismo notable al Tribunal Supremo Federal.

Como es sabido la Constitución no dejó clara la competencia sobre el control de constitucionalidad de las leyes, cuestión que fue resuelta jurisprudencialmente en el conocido caso Marbury v. Madison (1803), implantándose lo que se conoce como control difuso de constitucionalidad. Es un control que corresponderá a todo juez estatal o federal (es un control judicial y es difuso) y se producirá siempre en el curso de un proceso judicial (es un control incidental). Este tipo de control junto al principio de stare decisis y la obligación de los Tribunales inferiores de observar lo establecido por los Tribunales superiores (existiendo precedentes obligatorios y precedentes persuasivos), conducen al cierre de un sistema que, como todos, trata de generar un elemento de continuidad y uniformidad en el Derecho. Como consecuencia de esa mayor o menor persuasión del precedente, en el ámbito estatal la última palabra en ese control de constitucionalidad (y en el de legalidad) corresponde a los Tribunales Supremos del Estado y en el ámbito Federal al Tribunal Supremo norteamericano.

En coherencia con el diseño federal constitucional, de entrada, los Tribunales en cada orden jurisdiccional estatal o federal conocen de las materias que son competencia del Estado o de la federación, respectivamente. La jurisdicción federal tiene competencias delegadas limitadas, y no competencias plenas, que engloban solo una pequeña proporción de todas las controversias jurídicas. Con lo cual, los Tribunales estatales resuelven el resto de causas, esto es, aquellas controversias que quedan fuera de lo reservado a la justicia federal.

Cuando los Tribunales estatales resuelven deben atender al Derecho estatal y al Derecho federal ${ }^{22}$. De hecho, pueden conocer casos en los que se aplica el Derecho federal, salvo que esté previsto expresamente que dichas

ralización de materias penales que, tradicionalmente conocidas por los Tribunales estatales, han pasado a ser materia de Derecho federal, especialmente, en la última década del siglo xx. Ello genera dificultades de atribución y disfunciones, incluso con la existencia de penas diferentes para delitos en las leyes federales y estatales.

${ }^{22}$ Art. VI Constitución EE.UU.: «Esta Constitución, y las Leyes de los Estados Unidos que se expidan con arreglo a ella; y todos los Tratados celebrados o que se celebren bajo la autoridad de los Estados Unidos, serán la Ley Suprema del país; y los Jueces de cada Estado estarán por lo tanto obligados a observarlos, sin consideración de ninguna cosa en contrario en la Constitución o las leyes de cualquier Estado». 
materias o cuestiones sólo pueden ser conocidas por un Tribunal federal. En caso de conflicto entre el Derecho estatal y el Derecho federal, los Tribunales harán prevalecer el Derecho federal (Supremacy clause of the Constitution y otras).

Asimismo, los Tribunales estatales pueden resolver casos en los que tengan que aplicar Derecho de otro Estado. Y deben respetar las decisiones adoptadas por los Tribunales estatales de ese otro Estado ${ }^{23}$.

Por otro lado, los Tribunales federales también pueden conocer de casos fundados en el Derecho estatal cuando se alegan ambos, el Derecho estatal y el Derecho federal, en el pleito. Ahora bien, cuando un Tribunal federal decide una cuestión de Derecho estatal, está obligado a seguir la jurisprudencia del Tribunal superior de aquel Estado (Doctrina Erie ${ }^{24}$ ). Es decir, el Tribunal federal está obligado a interpretar la ley del Estado como la ha interpretado la Corte Suprema de ese Estado y, cuando no existe legislación sobre la materia, el juez federal está obligado a aplicar el Derecho común del Estado, de acuerdo con la jurisprudencia del Tribunal Supremo del Estado.

Pero, hay un punto de articulación fundamental entre ambas jurisdicciones, éste se encuentra en que las decisiones de los Tribunales Superiores de los Estados pueden ser revisadas por el Tribunal Supremo de la federación ${ }^{25}$, porque ninguna ley estatal o decisión judicial puede contravenir la Constitución de Estados Unidos, aunque pudiera ser acorde con la Constitución esta$\mathrm{tal}^{26}$. Eso significa que incluso en el caso en que la competencia en la regulación de determinadas materias corresponda a los Estados, si esta regulación puede afectar a cuestiones más amplias que afectan a derechos protegidos por la Constitución federal, o pudiera ser aplicable también Derecho federal, cabría la intervención última del Tribunal Supremo.

${ }^{23}$ Uno de los aspectos más importantes del federalismo para que la administración de justicia se cumpla y sea respetada en otros Estados es la garantía constitucional de lo que se llama «plena fe y crédito». Esta garantía requiere que los Tribunales de los Estados reconozcan como válidas las sentencias de los Tribunales de los otros Estados, siempre que el tribunal que dicte la sentencia tenga jurisdicción sobre la materia y las partes. Robert Baker, «El Federalismo y la administración de justicia en los Estados Unidos», Pensamiento Constitucional, año V, n. ${ }^{\circ} 5,69$.

${ }^{24}$ Gregorio Ruíz, Federalismo judicial (El modelo americano), (Madrid: Civitas, 1994), 171 y ss.

${ }_{25}$ Por ejemplo, un reo en el corredor de la muerte podría recurrir ante el Tribunal Supremo federal el método de ejecución decretado por un Estado alegando que es anormalmente doloroso y puede suponer un «cruel e inusual castigo», reconocido en la Octava Enmienda de la Constitución Federal.

${ }^{26}$ La competencia para revisar en apelación las resoluciones dictadas por los Tribunales estatales viene actualmente establecida en la Sección 1257 del Código Judicial Federal, en la redacción que le dio la reforma de 27 de junio de 1988. 
Lo cierto es que la posibilidad de que la jurisdicción federal revise las decisiones de los Tribunales estatales ha sido una batalla y sigue siendo una cuestión compleja y sensible ${ }^{27}$. En el fondo siempre ha latido la lucha entre los federalistas que han buscado ampliar la jurisdicción federal y la postura de los defensores de los derechos estatales, que han intentado mantener las prerrogativas de los Tribunales estatales, evitando la revisión de sus decisiones, suponiendo que éstos adoptarían una perspectiva más favorable a los intereses de los Estados ${ }^{28}$. Durante el liderazgo de Marshall ${ }^{29}$ el Tribunal Supremo bloqueó los esfuerzos de los Estados federados por rechazar el poder de apelación ante la judicatura federal y declaró inconstitucionales leyes aprobadas por más de la mitad de los Estados. Se convirtió así al Tribunal en el árbitro de las disputas entre Estados y de las que algunos de ellos pudiesen mantener con el gobierno federal $^{30}$. Con su jurisprudencia el Tribunal consiguió afirmarse como el máximo intérprete de la Constitución ${ }^{31}$. Con posterioridad a la guerra civil, se siguió ampliando la jurisdicción de los Tribunales federales permitiéndoles conocer de casos en los que derechos fundamentales quedaban afectados (Habeas Corpus Act, 1867 y Judiciary Act, 1875). Con ello se estaba autorizando a los Tribunales federales a controlar a los Tribunales estatales en casos penales para asegurar que los acusados no fueran encarcelados por violación del Derecho federal. En 1914 se aprobó una Ley que permitía al Tribunal Supremo revisar todas las decisiones judiciales estatales no sólo donde se alegase un precepto constitucional, sino también aquéllas en las que se alegase aplicación del Derecho federal frente al Derecho estatal que defendía una de las partes ${ }^{32}$. Durante los años 70 y 80 del siglo Xx los conservadores presentaron muchas propuestas con la finalidad de prohibir a los Tribunales federales el conocimiento de determinados asuntos, sin éxito. No obstante, no fue hasta 1995 cuando los republicanos consiguieron mayoría y aprobaron ciertas restricciones a la jurisdicción federal (en materia de revisión de cárceles y reducción de condenas). En definitiva, la cuestión sobre quién debe

${ }^{27}$ David A. Schlueter, «Judicial federalism and Supreme Court review of State Courts decisions: a sensible balance emerges», Notre Dame Law Review, vol. 59, issue 5, (1984): 1079-1117.

${ }^{28}$ G. Alan TARR, «Estados Unidos. Jurisdicción» en El federalismo judicial, ed. Por Manuel GERPE y Mercè BARCELÓ (coord.), (Barcelona: Institut d'Estudis Autonómics, 2006), 35 .

${ }_{29}^{29}$ Marshall fue juez del Tribunal Supremo de 1801 a 1835, cuando falleció.

30 Roberto Blanco VALdÉs, Los rostros..., 242.

31 Entre otros, asunto Marbury vs. Madison o Gibbons vs. Odgen.

32 Hasta 1914 la apelación de las sentencias dictadas por los Tribunales estatales no podía producirse mas que en dos casos concretos: cuando el Tribunal estatal hubiese invalidado una ley Federal y cuando los Tribunales hubieran mantenido la validez de una ley estatal frente a una reclamación basada en la Constitución o en las leyes federales. 
conocer de qué casos, si la jurisdicción federal o la estatal, ha sido un debate contante y sigue siendo discutida. De hecho, se apunta que en los últimos tiempos el Tribunal Supremo esta liderando un «federalism revival» (un resurgimiento del federalismo) ${ }^{33}$.

Decíamos que el Tribunal Supremo federal puede revisar las decisiones de los Tribunales de última instancia estatales. Normalmente esa última instancia reside en el Tribunal Supremo estatal, pero podría serlo un tribunal intermedio de apelación o una Trial Court, si su decisión constituye la última instancia en ese asunto en el Estado ${ }^{34}$.

El primer requisito a cumplir para recurrir ante el Tribunal Supremo de la Federación es que se hayan agotado las vías jurisdiccionales estatales. El objetivo es evitar cualquier indebida interferencia por parte del Tribunal Supremo Federal en la jurisdicción estatal hasta que los Tribunales de este orden hayan agotado toda posibilidad de resolver la controversia jurídica. Por ello, se requiere a la parte que promueve el recurso de revisión que haya alegado ante el tribunal estatal la aplicación del Derecho federal y lo haya hecho con suficiente claridad y antelación como para permitirle al juez estatal atender a ello.

En segundo lugar, el Tribunal Supremo solo puede conocer de casos resueltos por los Tribunales estatales cuando se trata de una controversia en la que era aplicable el Derecho Federal o se ha decidido indebidamente sobre una controversia a la que era aplicable el Derecho estatal, pero también el Derecho federal, y la correcta aplicación de este último era determinante para la resolución del conflicto. Es decir, puede que el Tribunal estatal solo haya aplicado Derecho estatal, pero cabía tener en consideración el Derecho federal, y ello era relevante para la decisión del caso. En este supuesto también cabe revisión ante el Tribunal Supremo.

Estamos hablando de lo que se denomina la doctrina del «independent and adequate state grounds» (independientes y suficientes fundamentos estatales). Lo que significa que la Corte Suprema estadounidense no pude revisar una decisión de un tribunal estatal si la decisión versa sobre una cuestión de Derecho estatal que es «independiente» (no depende del Derecho Federal, se puede resolver exclusivamente aplicando el Derecho estatal) y «suficiente» (ese Derecho estatal constituye un fundamento que, por sí solo,

${ }_{33}$ David S. Schwartz, «State Judges as Guardians of Federalism: Resisting the Federal Arbitration Act's Encroachment on State Law», University of Wisconsin Legal Studies Research Paper, n. ${ }^{\circ} 1380$ (2016).

${ }^{34}$ Grovey v. Townsend, 295 U.S. 45, 47 (1935); Talley v. California, 362 U.S., 60, 62 (1960); Thompson v. City of Louisville, 362 U.S. 199, 202 (1960); Metlakatla Indian Community v. Egan, 363 U.S. 555 (1960); Powell v. Texas, 392 U.S. 514, 516, 517 (1968); Koon v. Aiken, 480 U.S. 943 (1987). 
puede sustentar el fallo). En otras palabras, si la opinión del Tribunal Supremo norteamericano sobre las cuestiones federales del caso no cambiaría el resultado, porque la decisión final descansa sobre Derecho estatal no revisable, entonces el Tribunal Supremo no revisará el caso ${ }^{35}$.

El problema es que, en muchas ocasiones, los Tribunales estatales no precisan en sus sentencias si están resolviendo conforme al Derecho federal, conforme al Derecho estatal o conforme a ambos. Esa imprecisión judicial genera un dilema para el Tribunal Supremo estadounidense cuando se le presenta una decisión de un Tribunal Supremo estatal para revisión. Para ello, el Tribunal Supremo estableció una nueva regla en Micchigan v. Long, 463 U.S. $1302(1983)^{36}$. El Tribunal Supremo estadounidense señaló que si el Tribunal estatal desea evitar la presunción de que podía haberse aplicado Derecho federal, cuando ello se ha alegado en el juicio, debe dejar claro en su sentencia que el presunto Derecho federal no hubiese condicionado el resultado del fallo. Si ello no queda suficientemente claro, la Suprema Corte norteamericana asumirá que los «independientes y suficientes fundamentos estatales» no concurren en el caso y puede entrar a revisar la sentencia.

En todo caso, existe otro principio que trata de acomodar las interrelaciones entre los Tribunales federales y los Tribunales estatales que se denomina «comity». La noción de comity es una regla de autocontención judicial (ser comedido, tener deferencia con el otro tribunal) Esta regla sirve para atenuar los conflictos propios de la coexistencia de dos jurisdicciones y evitar conflictos de jurisdicción. No es una regla de Derecho, sino más bien una norma persuasiva.

\section{EL GOBIERNO DEL PODER JUDICIAL EN ESTADOS UNIDOS}

Como en otros aspectos la cuestión del gobierno del poder judicial responde también a ese modelo federal dual del que se viene hablando. Existe una forma de gobierno de los jueces de corte anglosajón que es particular para cada uno de los niveles jurisdiccionales, el federal y el estatal.

En el ámbito federal el gobierno del poder judicial corresponde a la Judicial Conference of the United States ${ }^{37}$, con el Presidente del Tribunal Supremo a la cabeza. Este órgano, no previsto en la Constitución, se creó en

${ }^{35}$ Cynthia L. FountAIne, «Article III and the adequate and independent state grounds doctrine», American University Law Review, vol. 48, (1999): 1053-54.

${ }^{36}$ Micchigan v. Long, 463 U.S. 1302 (1983).

${ }^{37}$ Un estudio más elaborado sobre el gobierno del poder judicial y el papel de la Judicial Conference es el realizado por, Elisenda CASAÑAS ADAM: «El poder judicial en Estados Unidos», en El poder judicial y modelo de Estado, ed. Por Manuel Gerpe y Miguel Ángel Cabellos (Barcelona: Atelier, 2013), 46 y ss. 
1922 con el objetivo de coordinar a los presidentes de las Circuit Courts y del Tribunal Supremo, a los efectos de redistribuir la asignación de jueces entre esos Tribunales de apelación. Con el tiempo se incluyó también la representación de los District Courts, de tal modo que actualmente este órgano está formado por los 13 Chief Justice de los Circuitos, 12 jueces de los Tribunales del Distrito, el Chief Judge del Tribunal de Comercio Internacional (Court of International Trade) y el Chief Justice del Tribunal Supremo ${ }^{38}$.

Las funciones que tiene asignadas la Judicial Conference son: a) Supervisar las condiciones del funcionamiento de los Tribunales federales; $b$ ) Planificar la asignación de jueces de los Tribunales de apelación a los de distrito o viceversa; c) Remitir sugerencias a los Tribunales federales para promover la uniformidad en los procesos y la gestión ágil del trabajo ${ }^{39} ; \mathrm{d}$ ) Revisar la decisiones sobre conductas disciplinarias e incapacidades adoptadas por los Consejos de Circuito; e) Analizar de manera permanente el efecto de las normas generales de procedimiento en los Tribunales; f) Supervisar la Administrative Office, que gestiona la administración de los medios materiales y personales de los Tribunales federales y las cuestiones de presupuesto; g) Supervisar el Federal Judicial Center, que trabaja en la mejora de la organización y funcionamiento del poder judicial federal y en la formación de jueces y personal al servicio del poder judicial; y h) También se le asignan a veces algunas otras funciones más relativas a la administración de los Tribunales.

La Administrative Office de los Tribunales federales, que acabamos de citar, es una agencia de asistencia legal, financiera, tecnológica, de gestión, y administrativa al servicio de los Tribunales federales. Gestiona la administración de los medios materiales y personales de dichos Tribunales. Es la encargada de llevar a cabo las políticas de la Judicial Conference, ofreciéndole, a ella y a sus comités, soporte y consejo, y es quien elabora desde 1939 el presupuesto judicial que luego tendrá que ser aprobado por el Presidente y el Congreso. El Presupuesto se presenta ante el Congreso por dos magistrados del Tribunal Supremo (para defender el presupuesto destinado al Tribunal Supremo) y dos representantes de la Judicial Conference y la Administrative Office para defender el resto del presupuesto del poder judicial. Es el Parlamento quien aprueba finalmente el presupuesto ${ }^{40}$, con el límite de no poder

3828 U.S. C. 15.

39 Para ello existen cinco Advisory Committes de la Judicial Conference encargados de enviar propuestas de reforma de las normas del proceso, respectivamente, en estos ámbitos: proceso civil, proceso penal, proceso de quiebra, proceso de apelación y reglas para la prueba.

${ }^{40}$ El Congreso aprueba el presupuesto y asigna fondos para que el Poder Judicial funcione. El presupuesto del Poder Judicial es una parte muy pequeña-0,2 por ciento- del 
rebajar nunca el salario de los jueces ${ }^{41}$. Ahora bien, una vez aprobado, la gestión corresponde a la Oficina Administrativa en colaboración con la Judicial Conference y los Circuit Judicial Councils.

En todo caso, la gestión y administración de cada tribunal federal está ampliamente descentralizada. Así, junto a lo anterior existen también, a nivel federal regional, los denominados Circuit Judicial Councils, que son unos Consejos presididos por el Chief Judge del Circuito y formados por un número similar de jueces de Circuito y de Distrito, elegidos entre ellos. Éstos supervisan algunos aspectos de la actuación de los Tribunales de apelación y de distrito. Así, tienen asignada la potestad disciplinaria en su Circuito ${ }^{42}$. Revisan las normas de funcionamiento de los Tribunales locales para adecuarlas con las normas federales procedimentales. Aprueban los planes de distrito en materias como la igualdad de acceso en el empleo o la selección del jurado. Y revisan las quejas por mal comportamiento judicial.

A ello hay que añadir una Judicial Conference of the Circuit en cada uno de los Circuitos, que está formada por todos los jueces del Distrito y del Circuito(s) y algunos abogados. Estos son órganos de discusión plenaria y asesores de los Circuit Judicial Councils.

Para cuestiones puramente administrativas en cada Tribunal de Circuito y Tribunal de Apelación existe un Clerk of the Court y su oficina que se encarga de la gestión de los casos, gestión del presupuesto y personal, de ofrecer información al público y de proveer al tribunal de determinados servicios como el de intérpretes u otros profesionales.

En el ámbito estatal se repite esa dualidad expresada en otros ámbitos del federalismo norteamericano, presentando una organización del gobierno de la judicatura separado del gobierno del poder judicial federal y no existiendo un único modelo de organización. Cada Estado lo organiza en su Constitución o en la legislación de forma particular. Con carácter general puede decirse que hay dos grandes modelos: la mayor parte de los Estados atribuyen el gobierno del poder judicial al Presidente del Tribunal Supremo estatal y un grupo más minoritario lo asigna al Tribunal Supremo estatal como órgano. Aunque también hay algún estado que atribuye dichas funciones de

monto total del presupuesto federal. (Oficina Administrativa de los Tribunales de los Estados Unidos: «El Sistema Federal Judicial en los Estados Unidos Presentación para Jueces y Personal Administrativo del Ramo Judicial en Países Extranjeros», Washington, D.C., 2000).

${ }^{41}$ Art. 3, secc. 1 de la Constitución: «Los jueces, tanto del Tribunal Supremo como de los inferiores, continuarán en sus funciones mientras observen buena conducta y recibirán en periodos fijos, una remuneración por sus servicios que no será disminuida durante el tiempo de su encargo».

${ }^{42}$ Las denuncias por conducta inapropiada o incapacidad contra un juez federal deben ser presentadas en la oficina judicial correspondiente. 
gobierno al Judicial Council (Consejo de la Judicatura), presidido por el Presidente de su Tribunal Supremo.

Todos ellos ejercen sus funciones de gobierno con plena autonomía en relación con los órganos de gobierno del poder judicial del resto de los Estados y de la Federación. El único órgano que actúa como foro de diálogo entre los diferentes poderes judiciales estatales es la Conference of Chief Justices, creada en 1949. El objetivo de la misma es hacer recomendaciones para la mejora de la administración de la justicia en los Estados.

En lo que respecta al presupuesto, la variedad vuelve a ser la nota destacable. La elaboración del presupuesto corresponde en cada Estado a un órgano diferente ${ }^{43}$. Puede serlo la Oficina administrativa de los Tribunales, o el Tribunal Supremo del Estado, o cada tribunal de modo individual. A continuación, ese presupuesto es revisado por el Tribunal Supremo del Estado y posteriormente es enviado al ejecutivo o al legislativo, según el Estado en el que nos encontremos. En el primer caso, con o sin enmiendas, el ejecutivo lo envía al parlamento, quien decidirá. La gestión, tras la aprobación del mismo, corresponde a la Oficina Administrativa de los Tribunales, bajo la dirección y supervisión de los órganos de gobierno del poder judicial estatal

También en las Constituciones estatales se pueden encontrar referencias a la prohibición de disminuir el sueldo de los jueces para garantizar su independencia económica.

\section{EL ESTATUTO JUDICIAL: LA SELECCIÓN, PROMOCIÓN, INDEPENDENCIA Y RESPONSABILIDAD DE LOS JUECES}

\subsection{Un sistema de selección de jueces plural ${ }^{44}$}

El sistema de elección de jueces de Estados Unidos es único. Y es único por varias razones: Ningún otro país tiene la pluralidad de métodos de selección de los miembros del poder judicial que tiene Estados Unidos, empezando por el modelo de selección de los jueces federales al empleado en cada uno de sus cincuenta Estados para seleccionar a los jueces estatales. Además, la gran mayoría de éstos últimos, bien para su elección o bien para mantenerse en el cargo, tienen que someterse al sufragio del pueblo. Y esa idea de votar a los jueces resulta absolutamente extraña para cualquier otro país. Incluso parece contradictoria con el concepto mismo de judicatura, siempre unida a principios

${ }^{43}$ En este punto seguimos el trabajo de Elisenda CASAÑAS ADAM, El poder judicial en Estados Unidos..., 60.

${ }^{44}$ Un trabajo mucho más detallado sobre la selección de jueces en EEUU puede verse en Rosario SERra Cristóbal, La selección de jueces en Estados Unidos, (Madrid: Civitas/Thomson Reuters, 2010). 
como la independencia, imparcialidad, neutralidad, apoliticidad, etcétera. Difícilmente puede encontrarse un lugar donde el nombramiento de los miembros del poder judicial tenga tantas connotaciones políticas.

a) Cuando los padres constituyentes establecieron este sistema de nombramiento de jueces federales lo hicieron sin saber si habría más Tribunales federales distintos del Tribunal Supremo y, en su caso, cuántos. Y lo hicieron pensando en un sistema que hiciera que el poder de seleccionar a un miembro del Tribunal Supremo no recayera en una sola rama del poder, si no que se produjera con participación de aquellos miembros del legislativo que entonces se consideraban más preparados para hacerlo, los de la Cámara alta ${ }^{45}$. Se conseguía así que en tal proceso participase un órgano que representaba a los Estados (el Senado) y otro que derivaba de la elección de la población (el Presidente), sin que ninguno de los dos tuviese la tentación de abusar de un posible poder de selección de jueces en exclusiva ${ }^{46}$.

Así, el sistema de nombramiento de jueces federales estadounidenses reside en una prerrogativa del Presidente que precisa del consejo y confirmación del Senado, lo cual obliga a un acuerdo de voluntades en el que intervienen múltiples intereses para la selección de unos jueces que ocuparán su cargo con carácter vitalicio. Los candidatos, que son propuestos por el Presidente ${ }^{47}$, pasan un primer y fundamental filtro en el Comité Judicial del Senado, donde participan en la práctica diferentes grupos de intereses que intentan imponer sus puntos de vista sobre los posibles candidatos, y donde se realizan comparecencias de los candidatos sometidos a un inquisitivo proceso de preguntas. Allí debe confirmarse al candidato por mayoría de los senadores que forman parte de ese Comité judicial. Superada la fase previa, se pasa el asunto

${ }^{45}$ Art. II, segunda sección, Constitución EEUU: El Presidente ... «propondrá y, con el consejo y consentimiento del Senado, nombrará los magistrados del Tribunal Supremo y a todos los demás funcionarios de los Estados Unidos cuya designación no provea este documento en otra forma y que hayan sido establecidos por ley».

${ }^{46}$ Puede verse, entre otros, los siguientes trabajos: DAvIs, Richard: Electing justice: fixing the Supreme Court nomination process (New York, Oxford University Press, 2005). Epstein, Lee y SEgal, Jeffrey: Advice and Consent: the politics of judicial appointments (New York, Oxford University Press, 2005). FABBrinI, Federico: «President Obama's first nomination to the Supreme Court: recent trends in the advice and consent procedure», Revista General de Derecho Público Comparado, 2010, n. ${ }^{\circ}$ 6, pp. 1-10.

${ }^{47} \mathrm{La}$ misma propuesta de candidato viene precedida de un proceso de búsqueda de potenciales candidatos que se inicia en el Departamento de Justicia de la Casa Blanca y en el que van interviniendo y ejerciendo presión grupos de intereses, lobbies de senadores, redes cercanas a los propios candidatos, la American Bar Association, etc. Incluso son sometidos a un severo escrutinio por el FBI. 
al Pleno. Una vez en el Pleno, si el propuesto no suscita controversias, generalmente obtiene el apoyo por unanimidad sin ser necesario un debate. En caso contrario, se abre este debate en la asamblea -debate en el que no está presente el candidato- y se realiza una votación nominal que requiere el respaldo de la mayoría de votos para considerarse aprobada la confirmación. Ahí es cuando se considera que el Senado ha otorgado su consent. Que duda cabe de que el hecho de que el partido del Presidente controle la mayoría del Senado es fundamental a la hora de asegurarse el nombramiento de su candidato. Cuando ello sucede, el $90 \%$ de los candidatos a jueces federales son aprobados, mientras que cuando el Senado no está controlado, sólo el 59\% de los propuestos presidenciales son finalmente confirmados ${ }^{48}$.

En la selección de los jueces federales, y en particular del Tribunal Supremo, la preservación del pluralismo y equilibrio entre varios factores como la raza, religión, origen, el género o lugar de procedencia, es un factor que se tiene mucho en consideración a la hora de que el Senado llegue a ese consenso necesario para apoyar el candidato del Presidente (y éste tiene en cuenta que pesará la busca ese equilibrio cuando propone un candidato $\left.{ }^{49}\right)$.

En la proposición presidencial de candidatos para el resto de Tribunales federales tiene mucho peso el parecer de los dos Senadores del Estado del candidato a juez. Lo que comenzó como una cortesía de consulta, se convirtió con el tiempo en un derecho de dichos senadores a vetar el candidato del Presidente. Hoy en día ello es más o menos así para los candidatos a jueces de Tribunales federales de Distrito, pero para los Tribunales intermedios de apelación el Presidente G. W Bush ya comenzó a mostrar menos deferencia a este respecto y lo mismo hizo el Presidente Obama, siendo sus propuestas más discrecionales ${ }^{50}$. Aún es pronto para saber cómo actuará el recientemente nombrado Presidente, D. Trump a este respecto, aunque podemos hacernos una idea.

De lo expuesto podemos concluir que del procedimiento de selección de jueces federales resulta la asunción de un poder judicial muy

${ }^{48}$ Pamela C. Corley, Artemus Ward, Wendy L. Martinek, American Judicial Process. Myth and Reality in Law and Courts, (New York: Routledge, 2016), 156.

49 Esa tendencia se observa en el aumento de la diversidad en las propuestas de candidatos a jueces federales presentadas por los últimos Presidentes. En particular, Obama nombró a más hispanos y americanos de origen asiático que nunca en la historia de Estados Unidos. Y lo mismo cabe decir de la presencia de mujeres, que se ha ido incrementando paulatinamente.

${ }^{50}$ Rachel BRAND, «Judicial appointments: checks and balance in practice», Harvard Journal of Law Review and Public Policy, vol. 33, (2010): 48-49. 
marcado por la política y la lucha de intereses. De hecho, desde 1933, cada vez que un partido alcanza la Presidencia acaba por controlar también la judicatura federal, aunque el riesgo de politización de estos jueces no se percibe como un problema apremiante ${ }^{51}$. Se pone como ejemplo el Tribunal federal del Decimocuarto Circuito como uno de los más liberales porque de 2011 a 2014, el Presidente Obama pudo nombrar a 6 de sus jueces ${ }^{52}$.

Obviamente, de entre los jueces federales, el nombramiento de los miembros del Tribunal Supremo es el que despierta el mayor interés social y político ${ }^{53}$, un interés que va más allá de las fronteras del propio país ${ }^{54}$, pero la selección del resto de jueces federales es igualmente muy relevante, pues la mayoría de los asuntos se resuelven en última instancia ante ellos y no llegan al Tribunal Supremo. Una importancia que se acrecienta cuando además nos encontramos en un sistema jurídico claramente jurisprudencial.

b) Sin embargo, los Estados federados no siguieron la estela marcada por la Constitución federal para los jueces de su ámbito territorial, siendo habitual que de un modo u otro, los jueces estatales tengan que someterse al escrutinio del electorado, algo totalmente ajeno a nuestra cultura judicial. La particularidad y el interés por el análisis del sistema de designación de jueces de Estados Unidos reside en que cada uno de los cincuenta Estados de la Unión tiene su propio modelo de designación de jueces, y distinto del sistema de selección de los jueces federales, lo cual lo hace muy atractivo para el estudioso del Derecho tanto foráneo como norteamericano. El modelo de selección de jueces por el que cada Estado ha optado puede venir recogido en su propia

${ }^{51}$ Diego Íñiguez HeRnándeZ, «Los sistemas de gobierno del poder judicial en el Derecho comparado» en, El Gobierno del Poder Judicial ed., M. GERPE y M.A. CABELlos (coords.), (Madrid: Marcial Pons, 2013), 41.

52 Pamela C. Corley, Artemus Ward, Wendy L. Martinek, American Judicial Process..., 120.

${ }^{53}$ Históricamente ha habido Presidentes que durante su mandato no han podido nombrar a ningún juez del Tribunal Supremo. En el lado contrario hay quien batió records como George Washington que nombró a 11 o F. Roosevelt que nombró a 9. Más recientemente, Clinton nominó a 2, G. W. Bush a 2, Obama a 2 y Trump está previsto que acabe nombrando entre 1 y 3 nuevos miembros de la Corte Suprema. Ahora mismo hay una vacante sobre la que el Presidente Trump ya ha realizado su propuesta ante el Senado. Al cierre de este artículo el proceso ante el Senado estaba sin concluir todavía.

${ }^{54}$ De ahí que el nombramiento de los magistrados del Tribunal Supremo sea un evento de general seguimiento en Estados Unidos, al igual que por la prensa y la academia del resto del mundo. Kosma, Monthomery N.: «Measuring the influence of Supreme Court Justices», The Journal of Legal Studies, vol. 27, n. ${ }^{2}$ 2, (1998): 333-373. 
Constitución de forma muy concreta ${ }^{55}$, o en ocasiones éstas dejan abierta la posibilidad de que el legislador estatal elija el sistema más apropiado para seleccionar a sus jueces ${ }^{56}$. Cada Estado puede escoger cómo acceden sus jueces a la judicatura, el periodo que pueden mantenerse en el cargo, la posibilidad de repetir en el mismo y otras variables más. Con todas las particularidades, en general, podemos decir que hay Estados donde los jueces son nombrados por el gobernador ${ }^{57}$, en otros por el legislador ${ }^{58}$, en otros por elecciones partidistas, o por elecciones no partidistas, y también podemos encontrarnos con Estados que establecen Comisiones judiciales para la propuesta de candidatos a jueces, pero donde éstos, una vez nombrados y pasado un periodo de tiempo, han de confirmar su cargo mediante una especie de consulta popular.

Esos diferentes mecanismos estatales de designación de jueces surgieron en un momento de la evolución de la democracia estadounidense que llevó a situar al pueblo como protagonista en múltiples espacios y entre ellos también en la elección de los que tenía que aplicar la ley: los jueces. En este sentido, éstos se asimilaron a los cargos representativos. Muchos de los jueces existentes durante lo que se denomina la democracia Jacksoniana (1830-1854) desautorizaron en su aplicación leyes que resultaban populares, lo que generó una reacción en un numero importante de Estados hacia un modelo de juez más cercano a los representantes legislativos.

Mississippi fue el primer Estado que impulsó una reforma del sistema de nombramiento de jueces introduciendo la elección popular y partidista de los mismos en 1832. Esta nueva idea de participación ciudadana en el poder judicial se extendió por todos los Estados de la Unión durante el siglo XIX, de ahí perviven hoy sistemas de selección de jueces donde los candidatos judiciales son presentados por los partidos a unas elecciones competitivas, o bien son los propios jueces los que se presentan a unas elecciones a imagen y semejanza de las elecciones políticas.

${ }_{55}$ Así sucede en el caso de Arizona, Colorado, Connecticut, Florida, Missouri, New Mexico, North Dakota, Hawaii, South Carolina, Vermont o Virginia, entre otros.

${ }_{56}$ Así, por poner un ejemplo, el Tribunal Supremo de Minnesota ya ha indicado en varias ocasiones, la última en Clark v. Ritchie, Minn Supreme Court, May 13 (2010), que la Constitución de este Estado no establece una preferencia inicial por un sistema de selección de jueces por delante de otro sistema.

57 Sólo tres Estados otorgan el nombramiento de sus jueces al Gobernador: California, Maine y New Jersey. Representan éstos un vestigio histórico de las colonias, cuando los jueces los nombraba el Rey inglés o los gobernadores designados en las colonias.

${ }_{58}$ Es el caso de South Carolina (con intervención de la Judicial Merit Selection Commission), y Virginia (con la intervención de un Advisory Committee). 
Esta práctica, que se generalizó en la gran parte de los Estados federados, sufrió serios reveses porque la incursión de los partidos políticos en la designación de jueces hizo saltar las alarmas, y con el tiempo el modelo ha sido abandonado en muchos Estados y sustituido por otras fórmulas ${ }^{59}$. Así, para paliar la excesiva politización de este sistema de elección de jueces, con el paso de los años, se han ido introduciendo modificaciones legislativas en los distintos Estados norteamericanos pasando de un sistema de selección partidista a un sistema de elección no partidista u otros sistemas, adoptando medidas correctoras a través de los Códigos de conducta judicial o estableciendo limitaciones legales en el proceso de selección, confirmación o renovación de los jueces en su cargo. La elección a través del sistema de «merit plans» es una consecuencia de ello. Son sistemas de selección de carácter mixto (en cuanto que interviene el ejecutivo y los otros poderes y unas Comisiones judiciales), donde se atiende preferentemente a los méritos de los candidatos, y en los que se refuerza el nombramiento con el apoyo popular a través de unas elecciones de confirmación (retention elections).

Lo cierto es que, sea cual sea el sistema de nombramiento de jueces estatales al que nos refiramos en EEUU, la connotación político-participativa está siempre presente.

\subsection{La promoción judicial en Estados Unidos}

Respecto a la promoción interna de jueces en la carrera, hablar de ello resulta difícil en general en el sistema estadounidense, y muy especialmente en el ámbito estatal, donde la selección de los jueces se realiza muchas veces con criterios partidistas y, en prácticamente casi todos los Estados, para un tiempo determinado.

Tampoco en el ámbito federal se puede decir que existe una promoción en la carrera judicial, pese a encontrarnos con la mayor parte de los cargos judiciales de carácter vitalicio.

Lo que sí es cierto es que, en la medida en que los méritos de los candidatos son tomados en consideración para su propuesta, bien por el equipo del Presidente para los jueces federales, o por las comisiones de nombramiento en los Estados con el sistema Missouri (Merit plans), el haber ocupado previamente una plaza de juez le otorga mayores probabilidades de ser propuesto

59 Bert BRANDENBURG, y Roy SchotLAND, «Judicial in peril: the endangered balance between impartial Courts and judicial election campaigns», Georgetown Journal of Legal Ehtics, Vol. 21, (2007): 1229-1258. 
como candidato con mayor idoneidad ${ }^{60}$. Así, por ejemplo, los últimos jueces nominados por los Presidentes para el Tribunal Supremo norteamericano habían sido previamente propuestos también para Tribunales de apelación por los mismos Presidentes que luego los nominaron para la Corte Suprema. Este es el caso de John Roberts, Clarence Thomas, David Souter, Robert Bork, Douglas Ginsburg o Antonia Scalia.

\subsection{Jueces independientes y responsables}

Como en cualquier sistema democrático del mundo, la máxima que se predica de los miembros de la judicatura es su independencia, y la confianza en que las decisiones de los jueces son adoptadas conforme a Derecho.

En Estados Unidos, por un lado, se quiso proteger la independencia de los jueces federales en el momento de acceder al tribunal, como hemos visto, a través de un sistema de nombramientos en el que se garantizaba que ninguno de los otros dos poderes por sí sólo pudiese determinar quiénes iban a conformarlos. Y por otro lado, se adoptaron medidas para garantizar su independencia una vez en el cargo, para asegurar que el desempeño de sus funciones no quedaría condicionado por las presiones provenientes de los otros poderes. De ahí la opción constitucional por un mandato de carácter vitalicio y con un sueldo no maleable (la imposibilidad del Congreso de minorar su salario $\left.{ }^{61}\right)$.

La misma independencia e imparcialidad se pretende de los jueces estatales. Recordamos de nuevo que estos principios constituyen la esencia del poder judicial de todo Estado democrático. Sin embargo, las medidas para salvaguardar la independencia del poder judicial en los Estados difieren bastante respecto de lo que hemos descrito en relación a la judicatura federal. Por lo pronto, pocos Estados ha optado por un sistema de nombramientos de jueces como el establecido en la Constitución federal ${ }^{62}$, y los Estados que han decidido nombrar a sus jueces con carácter vitalicio son escasos. No es que la independencia del poder judicial no sea un valor a perseguir, es que han decidido utilizar otros mecanismos para intentar asegurarla.

En los Estados que han escogido un sistema de elección popular de sus jueces, la independencia de los mismos se garantiza con la exigencia y

${ }^{60}$ Rachel BRAND, «Judicial appointmets: cheks and balance in practice», Harvard Journal of Law Review an Public Policy, vol. 33, (2010): 24-27.

${ }^{61}$ Sobre dicha garantía el Tribunal Supremo se pronunció en el caso O'Donoghue v. United State, 289 U.S. 516 (1933).

${ }_{62}$ Es el caso, por ejemplo, de New Jersey y Maine, aunque, a diferencia de los jueces federales, los jueces de estos Estados no son nombrados con carácter vitalicio sino por 7 años. Puede consultarse la tabla del anexo IV para otros ejemplos. 
respeto por parte de éstos de las reglas establecidas en el Código de conducta judicial de la American Bar Association (ABA) y los Códigos de conducta judicial estatales, inspirados en el primero. Los Estados que han optado por un sistema de nombramiento de jueces más fundado en los méritos de los candidatos, persiguen garantizar esa independencia con la intervención en el proceso de nombramiento no sólo del ejecutivo (y, a veces también legislativo), sino también de Comisiones en las que están representados diversos sectores de la sociedad y que proponen o informan candidaturas conforme a criterios objetivos y no partidistas.

El ideal de los constituyentes norteamericanos era disponer de unos jueces tanto en el ámbito estatal como federal que decidiesen los casos exclusivamente atendiendo a los dictados de la ley.

Que se busquen mecanismos para hacer a los jueces independientes no significa que puedan ser irresponsables, es decir, no puedan dejar de estar sujetos a normas jurídicas que permitan depurar sus responsabilidades cuando se desvían del imperio de la ley, al que están exclusivamente sometidos. Tal cosa haría de los jueces unos sujetos titulares de un poder sin control alguno que podría generar, paradójicamente, un daño a su propia independencia. En este sentido, los jueces han de ser responsables, precisamente porque son independientes. Pero, de otro lado, cuál sea el grado y ámbito de la responsabilidad judicial y cuál sea la instancia competente para depurar tal responsabilidad es determinante para asegurar esa independencia judicial. La responsabilidad no puede ser un reverso de la independencia que la anule ${ }^{63}$.

Con esta lógica, en la mayor parte de los países europeos se confía a los mismos jueces, y no a otros poderes del Estado, la potestad de sancionar conductas contrarias a Derecho. Lo cual no ha dejado de levantar suspicacias por la irresponsabilidad que el corporativismo puede acabar generando. En Estados Unidos la opción ha sido distinta.

Cuando se elaboró la Constitución norteamericana, se quiso que los jueces federales se mantuvieran de por vida en el cargo, como forma de garantizar su independencia, pero solo during good behavior, es decir, mientras ejercieran debidamente sus funciones (art. III.1 y art. II. 4 Constitución U.S). Por lo tanto, el modo de exigir responsabilidad por faltar a sus funciones -responsabilidad que supone la remoción en el cargo- es el impeachment. Históricamente su uso ha sido muy escaso. Por este procedimiento, que se inicia el Congreso y se decide en el Senado por mayoría de 2/3 de la Cámara, es altamente improbable que el cese de un juez pueda producirse por

${ }^{63}$ Rosario SERRA CRISTOBAL, «El juez responsable: una aproximación a las responsabilidades del juez desde un punto de vista comparado», Boletín de Información del Ministerio de Justicia, n. ${ }^{\text {o } 1982, ~(2005): ~ 5-16 . ~}$ 
misconduct ${ }^{64}$. En 1980 el Parlamento federal aprobó un sistema formal de responsabilidad disciplinaria para los jueces federales, que no afecta a los magistrados del Tribunal Supremo, mediante la aprobación de la Judicial Councils Reform and Judicial Conduct and Disability Act. Su origen se encuentra en el Código de Conducta Judicial que aprobó la Judicial Conference en 1973 sobre el modelo previamente aprobado por la American Bar Association (ABA). Conforme a este sistema se puede presentar una queja contra un juez federal ante el secretario del Tribunal de Apelación del Circuito, que la transmitirá al Presidente del Tribunal. Éste puede desestimarla o constituir una comisión especial para investigar la denuncia. En el primer caso cabe recurrir la decisión ante el Judicial Council del Circuito. En el segundo caso, la Comisión deberá presentar un informe con conclusiones y recomendaciones ante el Judicial Council del Circuito, que sancionará o hará sus propias investigaciones y decidirá. En caso de gravedad también puede remitirla cuestión a la Judicial Conference de los EEUU ${ }^{65}$. Entre las sanciones no cabe el cese del juez, que solo es posible a través del impeachment citado.

Sin embargo, en los Estados, al igual que no se alcanzó un acuerdo unánime sobre cómo elegir a sus jueces, tampoco se logró sobre cómo exigir de éstos responsabilidad por sus actuaciones. Pese a que se optó por copiar el modelo de control de los jueces con la adopción del impeachment ${ }^{66}$, el sistema de nombramiento judicial tan singular y variado de los estados ha dado lugar a otro tipo de responsabilidad judicial. El sistema de elección popular de jueces introdujo un nuevo modo de concebir la responsabilidad de los mismos más cercana a la responsabilidad y control al que se ven sometidos los representantes de los ciudadanos en las asambleas legislativa: la accountability. Los ciudadanos tienen un control formal sobre qué juez puede mantenerse en un cargo, incluso la posibilidad de expulsar a los que no hayan cubierto las expectativas de aquéllos. El voto permite a los ciudadanos apartar a aquellos candidatos más impopulares y promover a aquéllos que se ajustan más a los deseos y expectativas del cuerpo electoral ${ }^{67}$.

${ }^{64}$ Hasta 2000 tan sólo habían sido cesados por dicho procedimiento 7 jueces, pertenecientes a las U.S. District Courts, con independencia de algún caso más que se haya abierto sin aprobarse el impeachment. Patricia BARNES, Desk reference on American Courts (Washington: Congressional Quarterly Inc., 2000), 40. Ningún juez del Tribunal Supremo norteamericano ha sido destituido nunca.

${ }_{65}$ Casañas AdAM, El poder judicial en Estados Unidos..., 57.

${ }^{66}$ El impeachment está previsto en casi todos los Estados para cesar a un juez estatal, aunque su uso ha sido también muy escaso.

${ }^{67}$ Por ejemplo, estudios realizados han demostrado que en aquellos Estados donde una mayoría fuerte de la población está a favor de la pena de muerte, los jueces de apelación han sido menos partidarios de oponerse a ella en sus decisiones. Paul Brace y Brent 
Es más, cada sistema electoral está diseñado para producir un nivel distinto de responsabilidad del juez ante el electorado. Las elecciones de confirmación (retention elections) de un juez en su puesto son las que generan menos vínculo entre los ciudadanos y el electorado, mientras que las elecciones partidistas generan un tipo de responsabilidad electoral que no difiere mucho de la de los candidatos a cargos representativos. Éstas últimas tienen una mayor capacidad de generar vínculos entre los ciudadanos y los jueces $\mathrm{y}$, por lo tanto, la accountability del juez adquiere mayor relevancia ${ }^{68}$.

De todos modos, existe también ese tipo de responsabilidad disciplinaria al estilo europeo. Desde 1960 todos los Estados han adoptado un modo de controlar la conducta de los jueces mediante el respeto a los Códigos de conducta judicial estatales o acogiéndose al Código de Conducta Judicial de la ABA. En algunos Estados, la responsabilidad por la mala actuación de un juez es conocida por los jueces de la última instancia judicial dentro del Estado (el Tribunal Supremo estatal). En otros se ha establecido una Comisión disciplinaria que es la que se encarga de exigir este tipo de responsabilidad. En otros, las sanciones leves pueden ser adoptadas por la Comisión y las más graves por el Tribunal Supremo. De nuevo, la variedad de opciones está servida y el orden federal y el orden estatal funcionan de modo absolutamente autónomo.

\section{ALGUNAS REFLEXIONES FINALES EN TORNO A LA INTERSECCIÓN ENTRE LAS ORGANIZACIONES JUDICIALES ESTATALES Y FEDERAL}

Por todo lo expuesto se confirma que nos encontramos ante un sistema de federalismo judicial dual. Un sistema que mantiene altas cotas de autonomía entre la jurisdicción federal y la jurisdicción estatal. Esa autonomía entre la Federación y cada uno de los Estados y de éstos entre sí se materializa en prácticamente todos los ámbitos del poder judicial: en la formación y organización de los tribunales, en los mecanismos para seleccionar los jueces que los conformarán, en los sistemas escogidos para exigir responsabilidad de éstos, en el modo de gestionar los Tribunales, y en tantos aspectos más. Como se decía al comienzo, más bien podríamos decir que nos encontramos ante 51 sistemas judiciales, por la complejidad y diversidad que presentan. Ello tiene su razón de ser en la preexistencia de organizaciones judiciales

D. Boyea, «Judicial selection methods and capital punishment in the American States», en Running for judge. The rising political, financial and legal stakes of judicial elections, ed. Por Matthew J. Streb (New York: New York University Press, 2007), 183-203.

${ }^{68}$ Melinda GANN HaLl, «Competition as accountability in State Supreme Court elections», en Running for judge..., 166. 
propias en cada Estado antes de que se constituyese la Federación. La propia historia de formación de Estados Unidos y la vasta extensión territorial del país (que agudiza las singularidades de cada territorio y precisa de mayor descentralización) confluyeron en la necesidad de estructurar los 50 Estados bajo la forma de una Federación que mantuvo altos grados de soberanía de los Estados que la formaron y, por ende, de auto-organización en todos los ámbitos, incluido el judicial.

En consonancia con esa opción federal, a cada uno de los niveles jurisdiccionales (el Federal y el Estatal) se le atribuyó un ámbito competencial propio. Pero, cualquier reparto de competencias requiere de reglas de acomodación, porque hay materias donde la asignación jurisdiccional no queda clara, o son materias compartidas entre Federación y Estados, o simplemente el sistema precisa de una uniformidad y seguridad en la aplicación del Derecho. En este trabajo se han expuesto las vías que el federalismo judicial norteamericano ha buscado para salvaguardar el delicado equilibrio entre la autonomía de los Tribunales estatales y el papel del Tribunal Supremo norteamericano como árbitro final del Derecho Federal y máximo intérprete de la Constitución.

Quizás el momento donde ambas jurisdicciones interseccionan de forma evidente es cuando el Tribunal Supremo de la Federación revisa una decisión de un Tribunal estatal. Que el máximo órgano jurisdiccional de la federación pueda revisar las decisiones de los Tribunales superiores estatales constituye algo predecible en un sistema judicial federal. La no contradicción de las decisiones judiciales con el Derecho federal y, en concreto, con la Constitución federal, constituye una de las reglas básica sobre las que se sustenta la misma federación.

Sin embargo, esa posibilidad de revisión puede abrir la puerta a que desde la jurisdicción federal se pueda controlar el modo en el que los Tribunales estatales se organizan y gobiernan y eso sí constituye una materia tradicionalmente propia de la organización jurisdiccional de cada Estado. Es ahí donde parece caer el mito de que se trata de organizaciones jurisdiccionales -la estatal y la federal-, totalmente autónomas e independientes.

Por las limitaciones materiales de este estudio, solo pondremos algún ejemplo de decisiones adoptadas en el ámbito estatal sobre cuestiones de selección estatal de jueces u organización de tribunales, que acabaron siendo revisadas por el Tribunal Supremo federal por afectar a los derechos consagrados en la Constitución federal.

El Tribunal Supremo se ha pronunciado, así, sobre normas estatales que limitaban el gasto en la campaña electoral en las elecciones judiciales. El Tribunal Supremo siempre ha partido de la idea de que «cualquier ley que limite la libertad de expresión en una competición política está sometida a un severo escrutinio, ...siendo necesario que cualquier limitación a la libertad de 
expresión persiga un interés ineludible y ciñéndola al logro de tal interés» ${ }^{69}$. En el caso Brown v. Hartlage (1982) ${ }^{70}$ un candidato que se presentaba para ser elegido juez de Distrito (tribunal estatal) hizo promesas electorales que, en principio, contradecían la mencionada regla, la «anounce clause», establecida en la Ley de Corrupción de Kentucky. El Tribunal señaló que las leyes que limitan o prohíben la libertad de expresión de un candidato a juez sólo son admisibles si ello sirve a un interés estatal y, en todo caso, deben ser lo menos restrictivas posibles. El Tribunal entendió que lo único que justifica que a un juez se le limite su libertad de expresión durante la campaña electoral es el interés estatal de la imparcialidad y apariencia de imparcialidad que deben mantener los jueces. En definitiva, la jurisdicción federal entró a pronunciarse sobre el procedimiento electoral judicial establecido en la normativa estatal, asunto de la competencia del Estado. Ésta parece ser la tendencia seguida por el Tribunal Supremo estadounidense al respecto, que con el asunto Republican Party of Minnesota $v$. White (2002) ${ }^{71}$ dió otro revés a las announce clauses recogidas en diversos Códigos estatales de Conducta judicial. El Código de Conducta judicial de Minnesota venía estableciendo desde 1974 la prohibición a los candidatos de hacer públicos sus puntos de vista sobre materias legales controvertidas y cuestiones políticas -de nuevo la denominada «announce clause»-. En 1996 un abogado candidato a juez, durante su campaña electoral repartió cierta bibliografía criticando algunas decisiones judiciales en materias como aborto y otras cuestiones polémicas. Los hechos fueron recurridos y el Tribunal de apelaciones entendió que dicha limitación a la libertad de expresión tenía su justificación en la salvaguardia de la imparcialidad de los jueces o al menos en la imagen de imparcialidad de éstos y, por lo tanto, en el intento de generar una confianza del justiciable en la justicia ${ }^{72}$. Sin embargo, cuando el caso llegó al Tribunal Supremo norteamericano éste consideró que sí se había limitado la libertad de expresión del juez. De nuevo un Tribunal Federal acababa decidiendo en el cuestiones que pertenecen al proceso estatal de selección de jueces.

Hay otra sentencia del Tribunal Supremo que también puede afectar al proceso de elección judicial estatal que es la dictada en el asunto Citizens United v. Federal Election Commission, 2010 ${ }^{73}$. El Tribunal Supremo indicó que todos los ciudadanos, medios de comunicación y personas jurídicas, con

\footnotetext{
${ }^{69}$ WRLT, 551 U.S. at 464.

70456 U.S. 45 (1982).

${ }^{71}$ Republican Party of Minnesota v. White, 536 US 765 (2002).

${ }^{72}$ Republican Party of Minnesota v. Kelly, 247 f. 3d 854 (2001) Court of Appeals, 8th

${ }^{73}$ Citizens v. Federal Election Commission, 558 U.S. 50, (2010) La decisión Citizens United causó un gran revuelo entre los académicos y políticos, pues deja abierto el camino
} Circuit. 
o sin ánimo de lucro, tienen derecho a participar sin límites en el debate político mediante la inversión de dinero en la defensa de una idea o una causa, lo cual es aplicable a cualesquiera elecciones, incluidas las judiciales. La nueva doctrina camina hacia un sistema de desregularización de las aportaciones a las campañas electorales, algo que puede complicar aún más el problema de las ingentes sumas de dinero que mueven todo tipo de elecciones, con las corruptelas que ello puede acarrear y que son más preocupantes cuando hablamos de elecciones en el ámbito judicial.

En cuanto a la diversidad social en los sistemas de elección popular de jueces, cabe recordar como en Lousiana hubo un problema a raíz de la distribución de circunscripciones en el Estado y el número de jueces del Tribunal Supremo que les correspondía elegir a cada una de ellas. Un grupo de peticionarios de raza negra protestó porque el Distrito donde vivían, con una amplísima población negra, era al que le correspondía elegir el menor número de jueces en dicho Tribunal, lo cual acababa derivando en una menor representación de ciudadanos de color en dicho órgano. El asunto llegó al Tribunal Supremo de Estados Unidos que vino a decir que una práctica de este tipo vulneraba el derecho a un voto igualitario protegido en la Constitución y que ese derecho constitucional no está reservado exclusivamente para los comicios legislativos, sino que debía garantizarse igualmente las elecciones judiciales (Chisom v. Roemer, 501 U.S. 380 (1991) U.S. Supreme Court) ${ }^{74}$.

Valgan estos como botón de muestra de que, pese a encontrarnos ante un sistema de federalismo judicial dual, por vía de revisión judicial se producen las lógicas acomodaciones entre una organización judicial y la otra, que son necesarias por la convivencia bajo un mismo ordenamiento jurídico con la Constitución Federal a la cabeza.

\section{TITLE: American Judicial Federalism}

RESUMEN: El interés por el análisis del sistema judicial estadounidense reside en que cada uno de los cincuenta Estados de la Unión tiene su propio y particular modelo judicial, distinto además del sistema federal, lo cual lo hace muy peculiar y atractivo para el estudioso del Derecho. Este trabajo aborda el estudio del federalismo judicial dual que presenta

\footnotetext{
a la participación de corporaciones y uniones en las campañas electorales de todo tipo y deroga jurisprudencia anterior en esta materia, sentando nuevos precedentes.

${ }_{74}$ Lo mismo ha sucedido en otros Estados con un sistema de elección popular de jueces. Véase: White v. State of Alabama, 74 F. 3d 1058, (1996), Court of Appeals, 11th Circuit, o en South Christian Leadership Conference v. Evans, 785 F. Supp. 1469 (1992), U.S. District Court, M. D. Alabama, respect de Alabama. Y el asunto Brooks v. State Bd. of elections, 848 F. Supp. 1548 District Court, S. D. Georgia, Brunswick Div. (1994), respect de Georgia.
} 
este país y que se manifiesta en múltiples aspectos: la creación, organización y gobierno de los tribunales, la selección de jueces y exigencia de responsabilidad, o la distribución de competencias y articulación entre las distintas instancias jurisdiccionales.

PALABRAS CLAVE: Federalismo judicial, poder judicial en Estados Unidos, organización jurisdiccional federal, jueces, tribunales federales, tribunales estatales, gobierno judicial.

ABSTRACT: The interest in the analysis of the US judicial system is found in the fact that each of the fifty States of the Union has its own particular model of justice, different from the federal one. This makes it very peculiar and attractive to the law scholars. This essay deals with the study of the dual judicial federalism that this country presents and which manifests itself in many aspects: the creation, organization and governance of the courts, the selection of judges and the requirement of their responsibility, or the distribution of competences and articulation among the different Courts.

KEY WORDS: Judicial Federalism, Judicial Power in USA, Federal Jurisdiction, Judges, Federal Courts, State Courts, Judicial Governance. 